\title{
The optimization of ultrasonic-microwave assisted synergistic extraction of Lotus plumule extract rich in flavonoids and its hypoglycemic activity
}

\author{
Qiuzhe $\mathrm{Li}^{1 \dagger}$, Xiaoqing $\mathrm{Li}^{1^{\dagger}}$, Baodong Zheng ${ }^{1,2^{*}}$ and Chao Zhao ${ }^{1,2^{*}}$ (I)
}

\begin{abstract}
Lotus (Nelumbo nucifera Gaertn), a kind of perennial aquatic plant, is widely cultivated and consumed by people in Asian countries. Lotus plumule flavonoids (LPF) have been recognized as a hypoglycemic agent. LPF was optimally obtained using novel ultrasonic-microwave assisted synergistic extraction (UMSE) method by response surface methodology (RSM) on the basis of the results of single-factor experiments. Furthermore, the hypoglycemic activity of LPF was investigated by measuring the body weight, fasting blood glucose (FBG) level, and oral glucose tolerance test (OGTT) and analyzing the physiological indexes in streptozotocin-diabetic mice model. The optimum extraction conditions consisted of microwave power $355 \mathrm{~W}$, ultrasonic power $423 \mathrm{~W}$, extraction time 15 min, solidliquid ratio 1:40, ultrasound/interval time 1/0, and ethanol concentration 70\% with the maximum LPF yield of 2.62\%. LPF supplementation significantly decreased the body weight, FBG, OGT, serum total cholesterol (TC), serum total triglycerides (TG), and insulin levels, indicating the antidiabetic activity of LPF. This research verified that the UMSE technique was highly efficient to extract LPF to the maximum extent and the flavonoids from L. plumule exhibited hypoglycemic activity, which showed broad development and application prospects.
\end{abstract}

Keywords: Lotus plumule, Flavonoids, Ultrasonic-microwave assisted synergistic extraction, Hypoglycemic

\section{Introduction}

Diabetes mellitus (DM), a chronic metabolic disorder, is characterized by hyperglycemia syndrome and subsequently caused co-morbidities syndrome including hypertension, hyperlipidemia, and cardiovascular diseases (Rubio et al. 2008; Wan et al. 2020). DM has become a global public health issue with rapidly rising incidence. Besides, the type 2 diabetes mellitus (T2DM), also named non-insulin-dependent diabetes, takes up $90 \%$ of the diabetes (Zhao et al. 2019). The International Diabetes Federation reported that the diabetes is expected to reach 642 million by the year 2040 (Chan et al.

\footnotetext{
* Correspondence: zbdfst@163.com; zhchao@live.cn

${ }^{\dagger}$ Qiuzhe Li and Xiaoqing Li contributed equally to this work.

${ }^{1}$ College of Food Science, Fujian Agriculture and Forestry University, No.15

Shangxiadian Rd., Fuzhou, China

Full list of author information is available at the end of the article
}

2017). At present, a variety of oral anti-diabetic agents such as biguanides, sulfonylureas, $\alpha$-glucosidase inhibitors, and dietary glucose regulators could be used in clinical treatment, controlling blood glucose within in normal range (Dall et al. 2014; Natalia \& Montori, n.d.). However, these medicines might cause toxicity and serious side effects in a long-time cure (Vasconcelos et al. 2011). Therefore, the research for finding effective and natural hypoglycemic compounds which have less or no side effects is of great significance. In recent years, several studies have demonstrated that the medicinal plant extract presented antidiabetic activities (Soares et al. 2017; Testa et al. 2016), among which the flavonoids in the extract played an important part (Singab et al. 2005).

(c) The Author(s). 2021 Open Access This article is licensed under a Creative Commons Attribution 4.0 International License, which permits use, sharing, adaptation, distribution and reproduction in any medium or format, as long as you give appropriate credit to the original author(s) and the source, provide a link to the Creative Commons licence, and indicate if changes were made. The images or other third party material in this article are included in the article's Creative Commons licence, unless indicated otherwise in a credit line to the material. If material is not included in the article's Creative Commons licence and your intended use is not permitted by statutory regulation or exceeds the permitted use, you will need to obtain permission directly from the copyright holder. To view a copy of this licence, visit http://creativecommons.org/licenses/by/4.0/. 
Lotus (Nelumbo nucifera Gaertn) is a kind of perennial aquatic plant which were widely cultivated and consumed by people in Asian countries (Xiong et al. 2016). Almost every parts of lotus could be eaten while its green seed embryo, named Lotus plumule, was generally removed because it tastes bitter. In fact, $L$. plumule has been officially recognized as pharmaceutical and food resources in Chinese Pharmacopoeia for a long time (Ono et al. 2006). L. plumule exerted multiple pharmacological effects with high nutritional values, including anti-hypertensive, antiarrhythmic, anti-inflammatory, and anti-psychotic (Jun et al., 2016; Mukherjee et al. 2009; Sharma et al. 2017). Meanwhile, various bioactive ingredients and dietary nutrients were identified in lotus plumule, such as alkaloids, polysaccharides, flavonoids, tannins, and proteins. Limwachiranon et al. (2018) have reported that the total polyphenol and flavonoids content of lotus plumule were $29.0 \mathrm{mg} / \mathrm{g}$ and $18.9 \mathrm{mg} / \mathrm{g}$, respectively, which is consistent with Feng et al. (2016) and Liu et al. (2017) reported that the flavonoids content was $9.3-17.9 \mathrm{mg} / \mathrm{g}$. UPLC elution profile showed that the flavonoids content in crude $70 \%$ ethanol extract of Lotus plumule was higher than 50\% (Feng et al. 2016). Flavonoids were reported as the main bioactive component in L. plumule (Chen et al. 2012; Jiang et al. 2018a, 2018b). Although the bioactive effects including antioxidant and anti-inflammatory properties from $L$. plumule flavonoids (LPF) were well reported (Chen et al. 2019), systematic studies on their hypoglycemic activity remain elusive.

The traditional extraction methods of flavonoids commonly included reflux extraction (Liao et al. 2011), sonication extraction (Chen et al., 2019), microwave assisted extraction (Alara et al. 2018), and dynamic high pressure microfluidization-assisted extraction (Huang et al. 2013), which were time-consuming, solvent wasting, laborious, and finally with low extraction efficiency. Ultrasonicmicrowave synergistic extraction (UMSE) is a novel extraction technique which is fast, efficient, and economic. It combines with the ultrasonic and microwave, which takes the full advantages in the penetrating heating effect of microwave and cavitation of ultrasonic (Chemat \& Khan 2011; Mustapa et al. 2015). UMSE method is commonly selected for extracting flavonoids from medicinal plants, such as in sweet potato leaves (Liu et al. 2019), Cassia alata (Lin, Fun, Yeop, Yusoff, Gimbun 2019), and Spatholobus suberectus (Cheng et al. 2011). Response surface methodology (RSM) is an effective statistical technique which optimizes the multiple parameters. It is used for designing experimental experiments, modeling the extraction variables, verifying the statistical significance, and finally obtaining the optimum conditions of extracting LPF (Alara et al. 2017). Meanwhile, Box-Behnken design (BBD), a type of RSM independent design, is easy to establish and decode examination with highest adept than other designs ( $\mathrm{Li}$ et al. 2013).

In this study, total free and bound flavonoids were extracted from $L$. plumule by UMSE. The extraction efficiency of LPF was assessed with RSM coupled with BBD, determining the optimum processing parameters. The single-factor experiments, including ethanol concentration, solid-liquid ratio, ultrasound time/interval time, microwave power, ultrasonic power, and extraction time, were conducted in advance. In addition, the hypoglycemic activity of LPF was investigated by measuring the body weight, FBG level, and OGTT and analyzing the physiological indexes.

\section{Materials and methods}

\section{Materials and chemicals}

L. plumule was obtained from Jianning, Fujian, China. The samples were dried, ground into fine powder, and passed through 60 mesh sieves. Metformin hydrochloride sustained-release tablets were purchased from Yuekang Pharmaceutical Group Co., Ltd. (Beijing, China). Streptozotocin was purchased from Sigma Aldrich Co. (St. Louis, MO, USA). All chemical reagents were of analytical grade.

\section{Single factor for extraction efficiency of LPF by UMSE}

L. plumule powder $(5 \mathrm{~g})$ was extracted by Ultrasonicmicrowave device (XH-300B, Cheung Wing Technology Development Co., Ltd., China), which was set the microwave power of $300,350,400,450,500 \mathrm{~W}$ with the ultrasonic power of $200,400,600,800,1000 \mathrm{~W}$, immersed in ethanol solution of $10,30,50,70,90 \%$ at different solidliquid ratio $(\mathrm{g} / \mathrm{ml})$ of $1: 10,1: 20,1: 30,1: 40,1: 50$, using three types of ultrasound time/interval time of $1 / 2,2 / 1$, $1 / 0$, and continued for $5,10,15,20,25 \mathrm{~min}$. There were six parameters of ethanol concentration, microwave, ultrasonic power, solid-liquid ratio, ultrasound/interval time, and extraction time, respectively. While one factor was changed, the others were kept constant in single factor experiment. For example, the ethanol concentration, microwave, ultrasonic power, solid-liquid ratio, and extraction time were set at $70 \%, 350 \mathrm{~W}, 400 \mathrm{~W}, 1: 40$, and $15 \mathrm{~min}$ when the ultrasound/interval time was measured. The extraction solution was filtered and centrifuged at $4000 \mathrm{rpm}$ for $20 \mathrm{~min}$, and $30 \%$ ethanol was added into the supernatant to the volume of $500 \mathrm{~mL}$. The content of the LPF was quantified by HPLC with rutin was a standard using the method of Feng et al. (2016) referred. The extraction efficiency (\%) of LPF was calculated by the following equation:

$$
\text { Extraction efficiency }(\%)=\frac{m}{M} \times 100 \%
$$

Where $\boldsymbol{m}$ presented the $L$. plumule flavonoids content of 
extraction (g) and $\boldsymbol{M}$ was the actual mass of $L$. plumule (g).

\section{Experiment design of RSM}

Since 1:40 and 1:50 of solid-liquid ratio $(\mathrm{g} / \mathrm{ml})$ showed no obvious difference, $70 \%$ concentration of ethanol and $1 / 0$ ultrasound time/interval time had the best extraction efficiency of L. plumule flavonoids, considering saving the solvent, thus the solid-liquid ratio, ethanol concentration, and ultrasound time/interval time were set to 1 : $40,70 \%$, and $1 / 0$, respectively. Three other parameters that had more significant effects on extraction rate were optimized by RSM. It designed with three factors and three levels: microwave power (A), ultrasonic power (B), and extraction time $(\mathrm{C})$. The three single-factor levels were adopted to explore and optimize their independent and interactive impacts, which were settled down as A $(300,350,400 \mathrm{~W}), \mathrm{B}(200,400,600 \mathrm{~W})$, and C $(10,15$, $20 \mathrm{~min}$ ). Total seventeen combinations containing five replicates were produced by the Box-Behnken design as shown in Table 1. Each of them was repeated three times.

\section{Hypoglycemic activity of LPF Experiment animals}

A total of 60 male ICR Kunming healthy mice $(20 \pm 2 \mathrm{~g})$ were purchased from Shanghai SLAC Laboratory Animal Co., Ltd. (Shanghai, China). They were acclimatized for one week under standard ambient conditions (a 12/12 h light-dark cycle, temperature maintained at $25 \pm 3{ }^{\circ} \mathrm{C}$, and a suitable humidity of $50 \% \pm 10 \%$ ) with free access to normal diet and water. All animals were treated strictly in accordance with the guidelines for laboratory animal welfare ethics and daily animal care. The procedures were approved by the Ethics Review Committee of College of Food Science, Fujian Agriculture and Forestry University, China (No. FS-2017-002).

\section{Establishment of diabetic mice model}

Ten mice were assigned to feed normal diet, the other 50 mice were fed high-fat high-sucrose diet (HFHS, $63.6 \%$ basic forage, $15 \%$ sucrose, $10 \%$ egg yolk powder, $10 \%$ lard, $1.2 \%$ cholesterol, and $0.2 \%$ sodium cholate). After 30 days on feeding HFHS, 50 mice were fasted for $15 \mathrm{~h}$ with free access to water only, and then induced by intraperitoneal injections of freshly prepared streptozotocin (STZ, $100 \mathrm{mg} / \mathrm{kg}$ in $0.1 \mathrm{M}$ trisodium citrate-citric acid buffer, $\mathrm{pH}$ 4.2). The normal diet mice were given buffer only. Two weeks after injection, blood was taken from the tip of the mice tail vein to measure fasting blood glucose (FBG). The mice whose FBG levels were higher than $11.1 \mathrm{mmol} / \mathrm{L}$ were considered as T2DM mice (Chen et al. 2018). All mice in six groups were given accordingly treatment as specified below. The amount of intragastric administration was $0.5 \mathrm{~mL}$ per day for 3 weeks. The amount of 10 mice feeding normal diet was treated as normal group (NG), the other 50 mice which were fed HFHS were randomly divided into

Table 1 Box-Behnken design and predicted values of flavonoids from L. plumule

\begin{tabular}{|c|c|c|c|c|}
\hline \multirow[t]{2}{*}{ Run } & \multicolumn{3}{|l|}{ Factor } & \multirow{2}{*}{$\begin{array}{l}\text { Extraction } \\
\text { efficiency } \\
\text { of LPF (\%) }\end{array}$} \\
\hline & A: Microwave power (W) & B: Ultrasonic power (W) & C: Extraction time (min) & \\
\hline 1 & 400 & 600 & 15 & 2.33 \\
\hline 2 & 350 & 400 & 15 & 2.64 \\
\hline 3 & 300 & 600 & 15 & 2.24 \\
\hline 4 & 400 & 200 & 15 & 2.07 \\
\hline 5 & 350 & 600 & 20 & 2.01 \\
\hline 6 & 400 & 400 & 10 & 2.30 \\
\hline 7 & 350 & 400 & 15 & 2.65 \\
\hline 8 & 350 & 600 & 10 & 2.15 \\
\hline 9 & 350 & 400 & 15 & 2.66 \\
\hline 10 & 300 & 400 & 20 & 2.20 \\
\hline 11 & 350 & 400 & 15 & 2.65 \\
\hline 12 & 350 & 200 & 10 & 2.00 \\
\hline 13 & 350 & 200 & 20 & 1.93 \\
\hline 14 & 300 & 200 & 15 & 2.18 \\
\hline 15 & 300 & 400 & 10 & 2.21 \\
\hline 16 & 350 & 400 & 15 & 2.68 \\
\hline 17 & 400 & 400 & 20 & 2.14 \\
\hline
\end{tabular}


five groups (10 mice per group), the dosage regimens were designed as follows:

- Group 1: Normal group (NG) with physiological saline

- Group 2: Model group (MG) with physiological saline

- Group 3: Control group (CG) with $100 \mathrm{mg} /(\mathrm{kg} \cdot \mathrm{d})$ metformin hydrochloride

- Group 4: Low dose of LPF (LPF-L) with $200 \mathrm{mg} /$ (kg.d) L. plumule flavonoid extracts

- Group 5: Middle dose of LPF (LPF-M) with $400 \mathrm{mg} /$ (kg.d) L. plumule flavonoid extracts

- Group 6: High dose of LPF (LPF-H) with $800 \mathrm{mg} /$ (kg.d) L. plumule flavonoid extracts

\section{Clinical symptoms, body weight, and FBG measurement}

General daily observations were monitoring their food intake, drinking and urination consumption in each group. The body mass and fasting blood glucose of mice were measured and recorded on the 0th, 3rd, 7th, and 21st days, of which mice were fasted for $12 \mathrm{~h}$ before the determination of FBG. The bed material should be changed and alcohol disinfected after FBG analysis for preventing tail wound infection (Zhu et al. 2020).

\section{Oral glucose tolerance test}

On the 20th day of different diets treatment, mice in each group were given fasted for $5 \mathrm{~h}$ and gavage again subsequently. After $20 \mathrm{~min}$, all mice were administered glucose solution $(2 \mathrm{~g} / \mathrm{kg} \mathrm{BW})$. Blood samples were withdrawn from the tail for measuring FBG at $0 \mathrm{~h}, 0.5 \mathrm{~h}$, and $2 \mathrm{~h}$. The area under the curve (AUC) of glucose tolerance was determined as the equation follows:

$$
\operatorname{AUC}(\mathrm{mmol} / \mathrm{L})=\frac{0.5(A+B)}{2}+\frac{1.5(B+C)}{2}
$$

Where A, B, C presented the BG levels at $0 \mathrm{~h}, 0.5 \mathrm{~h}$, and $2 \mathrm{~h}$ respectively after administering glucose.

\section{Physiological index analysis}

On the 21st day of different diets treatment, mice in each group were fasted but can drink water freely for 8 h. The blood samples were collected from the orbital sinus and centrifugated $\left(12,000 \mathrm{r} / \mathrm{min}, 4^{\circ} \mathrm{C}\right)$ for $15 \mathrm{~min}$ to separate and transfer serum samples into microcentrifuge tube. Serum TG and TC were measured through their respective ELISA kits following the manufacturers' instructions (Jiancheng Bioengineering Institute, Nanjing, China). And serum insulin was determined using a corresponding ELISA kit (Xinyu Biotechnology Co., Ltd., Shanghai, China). Besides, the serum TG and TC levels were calculated as follows:

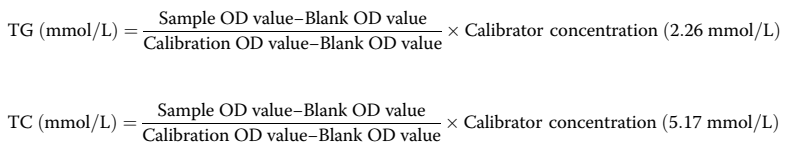

\section{Statistical analysis}

The Box-Behnken design and RSM values were processed used Design-Expert software (version 12.0.3.3, Stat-Ease, Inc.). Other experimental data were analyzed by SPSS version 22 software package for windows. Results were expressed as mean \pm standard deviation $(\mathrm{SD})$, and values were considered statistically significant when the $p$-values were less than 0.05 .

\section{Results and discussion}

\section{Analysis of extraction parameter influences}

The parameters which influence the extraction yield of LPF include ethanol concentration, solid-liquid ratio, ultrasound time/interval time, microwave power, ultrasonic power, and extraction time, the effects of them were evaluated through single factor experiments (Fig. 1). Ethanol has been widely used to extract biologically active compounds in different plants because of its low toxicity and inexpensive cost. The effect of ethanol concentration on the extraction efficiency of LPF was shown in Fig. 1a. As seen, the extraction rate peaked at 2.62\% at the concentration of $70 \%$, and then decreased. The reason may be that excessive ethanol concentration could make impurities such as polysaccharides and pigments dissolve into the solvent easily. Moreover, the extract solution appeared bright green color and the LPF sample was light in color in the treatment of $90 \%$ ethanol concentration during the experiment, which may be caused by excessive dissolution of chlorophyII. This result was in good agreement with those found by Liu et al. (Liu et al. 2019) who studied polyphenols from sweet potato leaves, as they also reported $70 \%$ as an optimum ethanol concentration.

It is important to maximize the extraction yield and reduce extraction solvent consumption, thus the feed-tosolvent ratio has been a research hotspot in industrial processes (Spigno \& Faveri 2009). The influence of solid-liquid ratio on the extraction efficiency was illustrated (Fig. 1b), and there was a significant improvement when the solid-liquid ratio increased from 1:10 to 1:40, but further increment was not obvious at 1:50. This might be due to the reason that flavonoids inside and outside the cell had reached the equilibrium of dissolution. In addition, larger amount of solvent needed more absorption of microwave power, which leads to insufficient energy diffusion to break the cell wall, thus slowing down the flavonoids leaching (Alara et al. 2018). Considering avoiding extra cost and inconvenient follow-up 

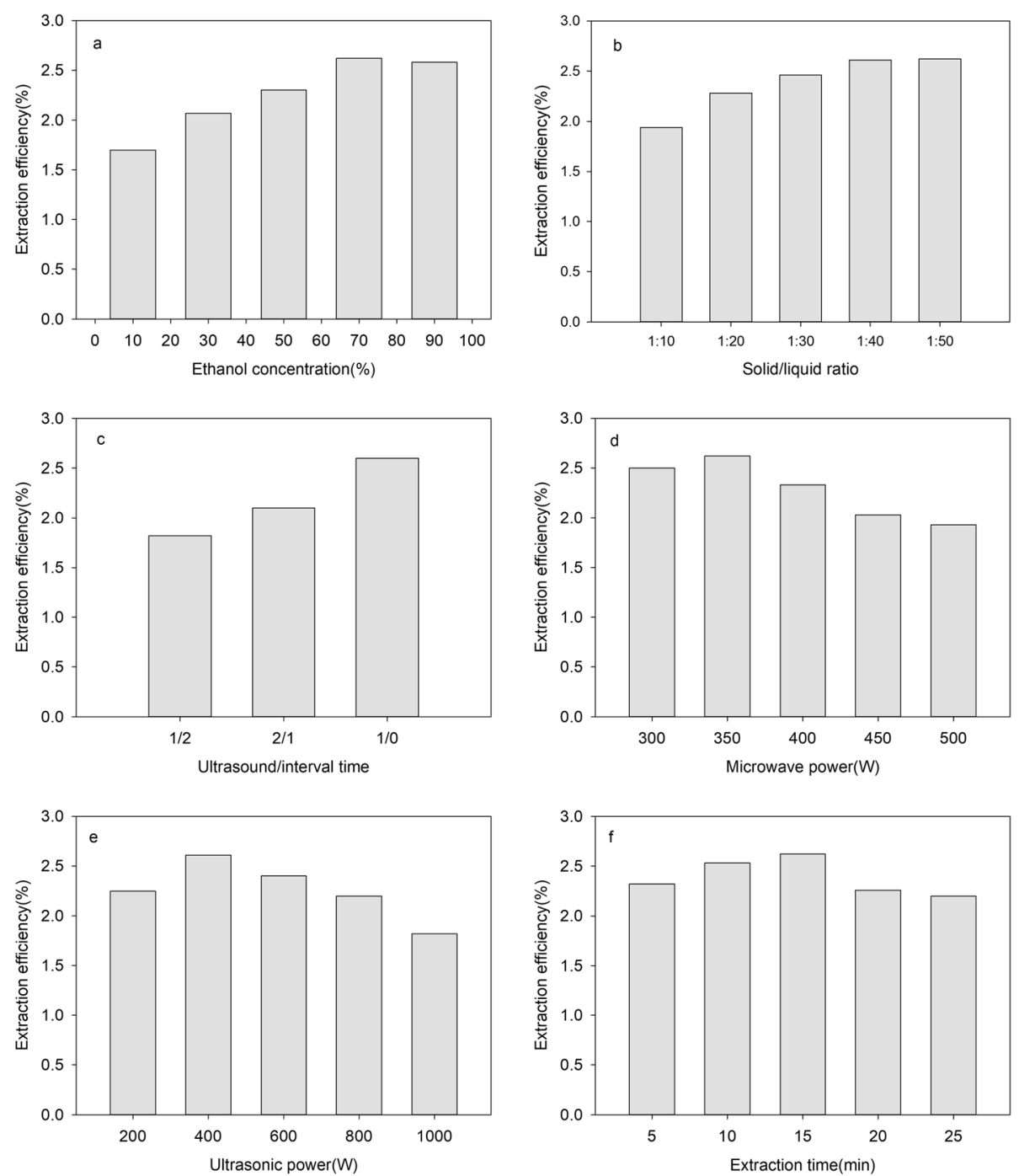

Fig. 1 (a) Influence of ethanol concentration on flavonoids extraction efficiency; (b) Influence of solid-liquid ratio on flavonoids extraction efficiency; (c) Influence of ultrasound/interval time on flavonoids extraction efficiency; (d) Influence of microwave power on flavonoids extraction efficiency; (e) Influence of ultrasonic power on flavonoids extraction efficiency; (f) Influence of extraction time on flavonoids extraction efficiency

concentration operation, the solid-liquid ratio of 1:40 revealed better.

Ultrasound/interval time represented the effect of different ultrasound methods (continuous or intermittent) on extraction rate (Fig. 1c). The yield of LPF gradually increased with an increase in ultrasound/interval time from $1 / 2$ to $1 / 0$, showing continuous ultrasound did better than intermittent ultrasound. This may be explained by continuous ultrasonication breaking down the cells more thoroughly, which was beneficial for the dissolution of flavonoids from $L$. plumule. Therefore, $1 / 0$ of ultrasound/interval time was chosen for LPF extraction. The influences of microwave power on LPF extraction efficiency were investigated under different ranges $(300-$ $500 \mathrm{~W})$. The extraction rate increased only when the microwave power level increased from 300 to $350 \mathrm{~W}$ (Fig. 1d). Beyond $350 \mathrm{~W}$, the rate declined significantly. Excessive microwave power resulted in accelerating flavonoids oxidation, leading to the degradation of flavonoid content (Dahmoune et al. 2014; Spigno \& Faveri 2009).

The ultrasonic power is one of the important parameters that affecting the extraction rate of LPF. As shown in Fig. 1e, the yield of LPF increased to the highest value of $2.62 \%$ at $400 \mathrm{~W}$ but then decreased sharply when the ultrasonic power was settled down higher. Suitable 
ultrasonic power would produce the phenomenon of ultrasonic cavitation, leading to the decomposition of the plant cell wall (Jalili et al. 2017; Zhu et al. 2015). However, with the continuous increase of ultrasonic power, the fragmentation effect of ultrasonic wave on the cells was enhanced, resulting in dissolution of impurities. In addition, the heat generated would destroy certain flavonoids, reducing extraction efficiency. The duration of extraction time is a key factor of extraction efficiency because microwaveand ultrasonic power require time to transfer the energy into the matrix (Liu, $\mathrm{Mu}$, Sun, \& Fauconnier, 2019). The extraction yield had remarkable enhancement and then achieved to maximum when the time lasting to 15 min compared to 5 $\mathrm{min}$ and $10 \mathrm{~min}$, but quickly decreased at $20 \mathrm{~min}$ (Fig. 1f). This result might be interpreted that the extraction time can break plant tissue structure thus enhancing the reactive site in the effective extraction process by ultrasonic cavitation and microwave irradiation (Arasi et al. 2016). However, extended period caused plant matrix excessive exposed to the microwave radiation, probably leading to the thermal degradation of flavonoid compounds (Dahmoune et al., 2014; Xu et al. 2012).

\section{Statistical analysis and model fitting using RSM}

In order to optimize the influences of single variables and experiment time, finally acquiring the maximum extraction efficiency, the response surface methodology analysis and Box-Behnken design was conducted. The analysis of variance was depicted in Table 2 . Using the multiple regression analysis, the extraction rate was estimated by the second-order polynomial equation: $Y=$ $2.66+0.0012 A+0.0688 B-0.0475 C+0.050 A B-$ $0.0375 A C-0.0175 B C-0.1305 A^{2}-0.3205 B^{2}-0.3130 C^{2}$

where Y represents the yield of LPF and A, B, and C are factors for microwave power (W), ultrasonic power $(\mathrm{W})$, and extraction time (min), respectively. F-test and $P$-value were used to check the statistical significance of each coefficient in the regression model. In this table, linear coefficients ( $B$ and $C)$, interaction coefficients $(A B$ and $\mathrm{AC})$, and quadratic coefficients $\left(\mathrm{A}^{2}, \mathrm{~B}^{2}\right.$, and $\left.\mathrm{C}^{2}\right)$ were found significantly affecting extraction rate $(p<0.05)$, indicating these factors were quite important to the extraction rate of $L$. plumule flavonoids. The $p$ value of the model was less than 0.0001 , presenting the model was proximately to the reality. The determination coefficient $\left(R^{2}=0.9977\right)$ showed that $99.77 \%$ of real extraction process could be explained, just $0.23 \%$ could not be clarified (Wai et al. 2010), indicating the model was able to make good prediction under the range of experimental variables. Likewise, the value of "the lack of fit" parameter was insignificant $(p=0.2294>0.05)$, which represented that the regression model was significant compared with the pure error. Therefore, these data clearly showed the reliability of the experimental value in the model.

\section{Analysis of response surface plots}

The 3D response surface reflected the relationship between two variables among microwave power, ultrasonic power, and extraction time (Fig. 2a-c). Ultrasonic power presented the most important factor $(p$-value $<0.0001)$, affecting the extraction efficiency of LPF effectively. At

Table 2 Analysis of variance of response surface quadratic model

\begin{tabular}{|c|c|c|c|c|c|}
\hline Source & Sum of squares & df & Mean squares & F-Value & $p$-value Prob $>F$ \\
\hline Model & 1.080943 & 9 & 0.1201048 & 343.8583 & $<0.0001$ \\
\hline A-Microwave power & 0.0000125 & 1 & 0.0000125 & 0.035787 & 0.8553 \\
\hline B-Ultrasonic power & 0.037813 & 1 & 0.0378125 & 108.2566 & $<0.0001$ \\
\hline C-Extraction time & 0.01805 & 1 & 0.01805 & 51.67689 & 0.0002 \\
\hline$A B$ & 0.01 & 1 & 0.01 & 28.62986 & 0.0011 \\
\hline$A C$ & 0.005625 & 1 & 0.005625 & 16.10429 & 0.0051 \\
\hline$B C$ & 0.001225 & 1 & 0.001225 & 3.507157 & 0.1033 \\
\hline$A^{2}$ & 0.071706 & 1 & 0.0717063 & 205.2942 & $<0.0001$ \\
\hline$B^{2}$ & 0.432506 & 1 & 0.4325063 & 1238.259 & $<0.0001$ \\
\hline$C^{2}$ & 0.412501 & 1 & 0.4125011 & 1180.985 & $<0.0001$ \\
\hline Residual & 0.002445 & 7 & 0.0003493 & & \\
\hline Lack of fit & 0.001525 & 3 & 0.0005083 & 2.210145 & 0.2294 \\
\hline Pure error & 0.00092 & 4 & 0.00023 & & \\
\hline Cor total & 1.083388 & 16 & & & \\
\hline$R^{2}$ & 0.9977 & & & & \\
\hline
\end{tabular}




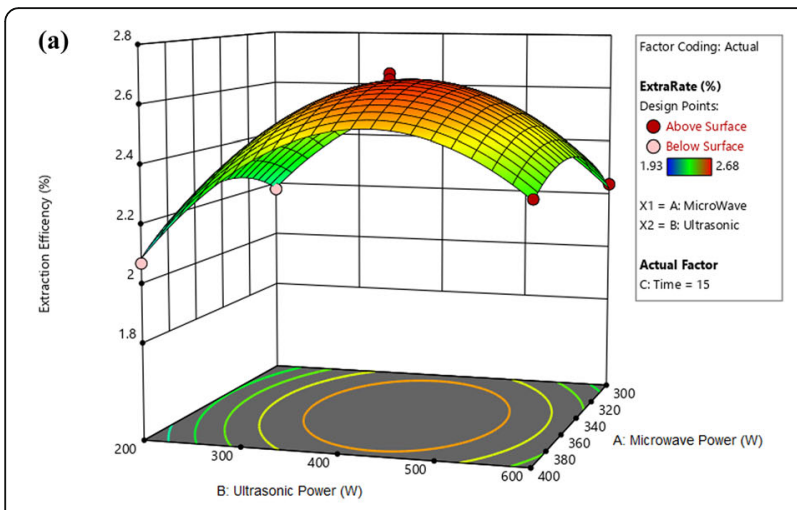

(b)
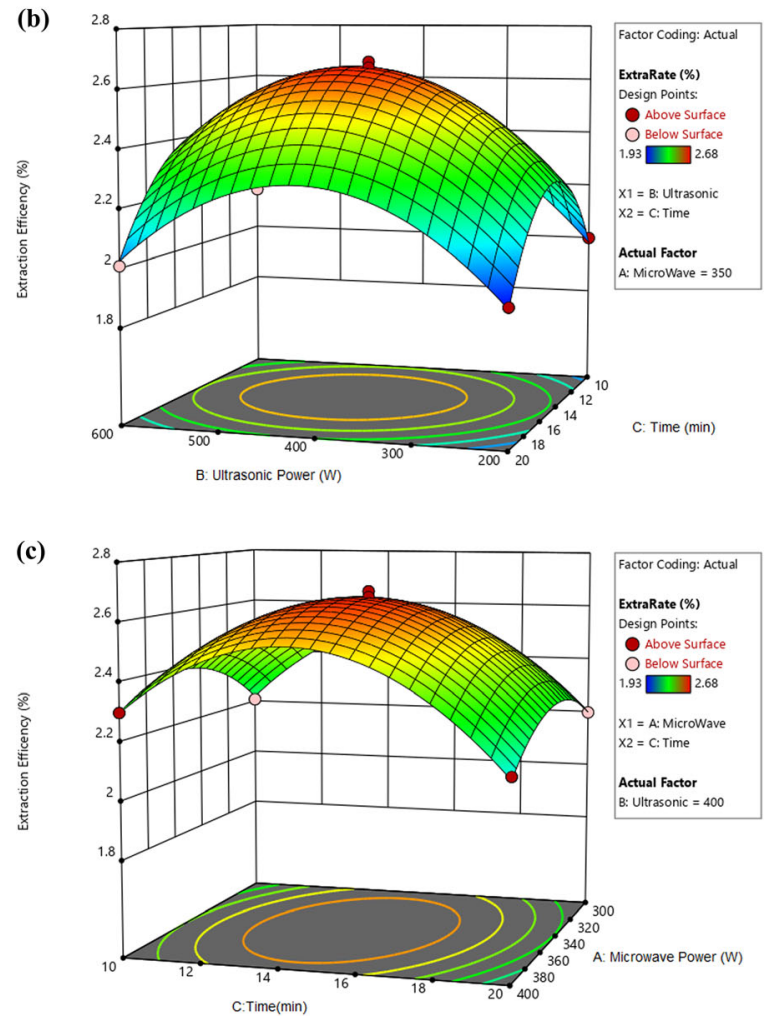

Fig. 2 (a) Interactive effects of microwave power and ultrasonic power; (b) Interactive effects of ultrasonic power and time; (c) Interactive effects of microwave power and time

fixed extraction time of $15 \mathrm{~min}$, with the enhancing of ultrasonic power or microwave power, the extraction yield of LPF was appeared first rising but then falling tendency (Fig. 2a). The influence of both parameters on the extraction rate showed a certain degree of similarity. The extraction yield of LPF increased linearly with the increase of ultrasonic power and extraction time in a certain range (Fig. 2b). And the peak yield was obtained when ultrasonic power and extraction time were $400 \mathrm{~W}$ and $25 \mathrm{~min}$, respectively, which the microwave power was set to $350 \mathrm{~W}$. The interaction of microwave power and extraction time on the yield of LPF were shown (Fig. 2c).
The extraction rate climbed to highest when microwave power was $350 \mathrm{~W}$ and extraction time was $15 \mathrm{~min}$.

\section{Model verification}

The model equation was verified by the results of response surface analysis. The optimal extraction conditions were predicted as: $352 \mathrm{~W}$ of microwave power, $423 \mathrm{~W}$ of ultrasonic power, $14.6 \mathrm{~min}$ of extraction time, 1:40 of solid-liquid ratio, 1/0 of ultrasound/interval time, and $70 \%$ ethanol concentration, which the predicted extract efficiency was $2.68 \%$. In order to further explain the deviation between the actual value and the predicted value and consider the practical operation, the experiment rechecking was conducted using following modified conditions: microwave power $355 \mathrm{~W}$, ultrasonic power $423 \mathrm{~W}$, extraction time $15 \mathrm{~min}$, solid-liquid ratio $1: 40$, ultrasound/interval time $1 / 0$, and ethanol concentration $70 \%$. The actual extraction rate reached $2.62 \%$, which represented not significant to the predicted value, clarified the validation of RSM model, and finally indicated that the predicted model was adequate and accurate for this research.

\section{Hypoglycemic effect analysis of LPF Daily status of T2DM mice}

The number of 50 T2DM mice had greater food and water consumption compared to the normal group. Besides, significant differences were observed on cage padding and defecated situation between T2DM mice and normal mice, where T2DM mice showed moist cage padding and thin stools. These behaviors were consistent with the typical diabetic symptoms as "polyphagia, polydipsia, urorrhagia, and loss of body weight", which called "three more and one less". It was observed that the " three more and one less "symptoms of mice in control group, LPF-L group, LPF-M group, and LPF-H group were all alleviated during the progress of administration, while the model group got worsened with time, indicating the potential of improving anti-diabetic effect from L. plumule flavonoids.

\section{Effect of LPF on body weight in T2DM mice}

Overweight is one of the characteristics on type 2 diabetes, but it would be relieved in the clinically treatment. The variation of the mice body weight was measured on the day $0,7,14$, and 21 during administration (Table 3). Before flavonoids administration, the body weights of MG, CG, LPF-L, LPF-M, and LPF-H groups were obvious higher than that of the normal group $(p<0.01)$, indicating that T2DM mice were successfully established and were appropriate for subsequent experiments. Minor increases were observed in the normal and model groups, but the body weights of the control group and different dose of the LFP groups were decreased during 
Table 3 Effect of flavonoids from L. plumule on body weight of diabetic mice

\begin{tabular}{|c|c|c|c|c|}
\hline \multirow[t]{2}{*}{ Group } & \multicolumn{4}{|c|}{ Body weight (g) } \\
\hline & Day 0 & Day 7 & Day 14 & Day 21 \\
\hline Normal & $37.76 \pm 0.94^{B D}$ & $39.57 \pm 0.99^{B D}$ & $40.84 \pm 0.76^{\mathrm{BD}}$ & $41.61 \pm 0.66^{B}$ \\
\hline Model & $49.06 \pm 1.49^{\mathrm{A}}$ & $50.57 \pm 1.53^{\mathrm{AD}}$ & $50.98 \pm 1.36^{\mathrm{AD}}$ & $51.28 \pm 1.13^{A D}$ \\
\hline Control & $48.58 \pm 2.74^{\mathrm{A}}$ & $47.60 \pm 2.50^{\mathrm{AB}}$ & $45.77 \pm 2.16^{\mathrm{AB}}$ & $43.33 \pm 2.97^{B}$ \\
\hline LPF-L & $47.94 \pm 2.65^{\mathrm{A}}$ & $47.31 \pm 2.24^{\mathrm{AB}}$ & $46.97 \pm 2.70^{\mathrm{AB}}$ & $46.62 \pm 2.00^{\mathrm{ABd}}$ \\
\hline LPF-M & $48.53 \pm 2.40^{\mathrm{A}}$ & $47.23 \pm 2.69^{A B}$ & $45.03 \pm 2.59^{A B}$ & $44.06 \pm 2.11 \mathrm{aB}$ \\
\hline LPF-H & $48.12 \pm 2.85^{\mathrm{A}}$ & $46.84 \pm 2.59^{\mathrm{AB}}$ & $45.88 \pm 2.26^{\mathrm{AB}}$ & $45.47 \pm 2.22^{\mathrm{AB}}$ \\
\hline
\end{tabular}

21 days of treatment. The control and LPF groups represented huge reductions in body weight $(p<0.01)$ than the model group, of which the control group and the LPF-M group showed the largest decline. The LPF-L, LPF-M, and LPF-H groups showed insignificant difference compared with control group, demonstrating that L. plumule flavonoids could effectively control the body weight of T2DM mice. In addition, the body weights of mice in three LPF groups were still higher than the normal group in the 21th day, which indicated that L. plumule flavonoids were unable to completely decrease the body weight back to normal level. It might because $L$. plumule flavonoids could not completely repair the islet cell damage induced by STZ (Zhu et al. 2020).

\section{FBG levels in T2DM mice}

The FBG levels in the normal group mice were maintained at a stable normal level during the 21-day administration (Table 4), suggesting experimental environment and eating diet did not affect normal glucose metabolism. After 7 days, three doses of LPF all exhibited significant hypoglycemic effects $(p<0.01, p<0.05$, and $p<0.01$ ) of streptozotocin-diabetic mice compared with the model group. Moreover, there was no significant difference between the control group and LPF-M group as well as LPF-H group, of which the anti-diabetic effect of middle dose was equivalent with $100 \mathrm{mg} /(\mathrm{kg} \cdot \mathrm{d})$ metformin hydrochloride. Therefore, L. plumule flavonoids treatment had notable hypoglycemic effect.

\section{Oral glucose tolerance test in T2DM mice}

The oral glucose tolerance test (OGTT) could measure the ability to regulate blood glucose after taking glucose, which is the major method for diabetes diagnosis ( $\mathrm{Zhu}$ et al. 2020). The blood glucose levels exerted remarkable increases in T2DM mice after glucose administration (Table 5), while the LPF-group of three doses saw modest rises compared to the model group, suggesting $L$. plumule flavonoids could suppress the sharp increase in blood glucose level. The LPF-M group and LPF-H group exerted no significant difference to control group, which indicated the excellent modulating effect on OGTT. Besides, the AUC of the control, LPF-L, LPF-M, and LPF$\mathrm{H}$ groups showed significant reduction $(p<0.05)$ compared with the model group (Fig. 3). Thus, flavonoids from L. plumule could utilize the glucose well and significantly improve glucose tolerance in T2DM mice.

\section{Effects of LPF on serum TG, TC, and insulin levels of T2DM mice}

Dyslipidemia is one representative symptom of T2DM patients. And the T2DM-related hyperlipidemia would also cause cardiovascular disease (Yan et al. 2019). In comparison with the model group, the levels of serum TG and TC revealed considerable diminution after the

Table 4 Effect of flavonoids from L. plumule on serum glucose of diabetic mice

\begin{tabular}{|c|c|c|c|c|}
\hline \multirow[t]{2}{*}{ Group } & \multicolumn{4}{|l|}{ FBG (mmol/L) } \\
\hline & Day 0 & Day 7 & Day 14 & Day 21 \\
\hline Normal & $5.47 \pm 0.31^{B D}$ & $5.64 \pm 0.75^{\mathrm{BD}}$ & $5.35 \pm 0.79^{B D}$ & $5.5 \pm 0.46^{\mathrm{Bd}}$ \\
\hline Model & $12.79 \pm 2.16^{\mathrm{A}}$ & $13.16 \pm 1.92^{A D}$ & $12.85 \pm 1.83 \mathrm{AD}$ & $12.59 \pm 1.54 \mathrm{AD}$ \\
\hline Control & $11.96 \pm 1.22^{\mathrm{A}}$ & $9.43 \pm 1.95^{\mathrm{AB}}$ & $8.18 \pm 1.97^{A B}$ & $6.83 \pm 1.68^{a B}$ \\
\hline LPF-L & $12.52 \pm 1.57^{\mathrm{A}}$ & $10.97 \pm 2.05^{A b}$ & $9.87 \pm 1.47^{\mathrm{ABd}}$ & $9.25 \pm 1.05^{\mathrm{ABD}}$ \\
\hline LPF-M & $12.60 \pm 1.45^{\mathrm{A}}$ & $10.24 \pm 2.19^{A B}$ & $8.68 \pm 1.87^{A B}$ & $7.18 \pm 1.50^{\mathrm{aB}}$ \\
\hline LPF-H & $12.95 \pm 2.03^{A}$ & $11.17 \pm 1.63^{\mathrm{Ab}}$ & $9.49 \pm 1.56^{\mathrm{AB}}$ & $8.11 \pm 1.27^{\mathrm{AB}}$ \\
\hline
\end{tabular}

The results were expressed as mean \pm SD ( $n=8 /$ group). ${ }^{\mathrm{A}} p<0.01,{ }^{\mathrm{a}} p<0.05$, compared with normal group; ${ }^{\mathrm{B}} p<0.01,{ }^{\mathrm{b}} p<0.05, \operatorname{compared}$ with model group; ${ }^{\mathrm{D}}$ $p<0.01,{ }^{\mathrm{d}} p<0.05$, compared with control group 
Table 5 Effect of flavonoids from L. plumule on glucose tolerance of diabetic mice

\begin{tabular}{llll}
\hline Group & \multicolumn{3}{l}{ Blood glucose level (mg/dl) } \\
\cline { 2 - 4 } & $\mathbf{0 ~ h}$ & $\mathbf{0 . 5} \mathbf{h}$ & $\mathbf{2 ~ h}$ \\
\hline Normal & $5.5 \pm 0.29^{\mathrm{Bd}}$ & $10.15 \pm 1.38^{\mathrm{B}}$ & $5.98 \pm 1.02^{\mathrm{Bd}}$ \\
Model & $12.56 \pm 1.58^{\mathrm{AD}}$ & $20.16 \pm 2.43^{\mathrm{AD}}$ & $15.71 \pm 3.13^{\mathrm{AD}}$ \\
Control & $7.07 \pm 1.46^{\mathrm{aB}}$ & $11.23 \pm 1.52^{\mathrm{B}}$ & $7.94 \pm 1.23^{\mathrm{aB}}$ \\
LPF-L & $9.21 \pm 1.05^{\mathrm{ABD}}$ & $16.78 \pm 1.85^{\mathrm{ABD}}$ & $11.65 \pm 2.16^{\mathrm{ABD}}$ \\
LPF-M & $7.36 \pm 1.62^{\mathrm{AB}}$ & $13.58 \pm 2.40^{\mathrm{ABd}}$ & $7.75 \pm 1.34^{\mathrm{aB}}$ \\
LPF-H & $7.98 \pm 1.67^{\mathrm{AB}}$ & $14.82 \pm 2.56^{\mathrm{ABD}}$ & $9.34 \pm 1.26^{\mathrm{AB}}$ \\
\hline
\end{tabular}

The results were expressed as mean $\pm \mathrm{SD}$ ( $\mathrm{n}=8 /$ group). ${ }^{\mathrm{A}} p<0.01,{ }^{\mathrm{a}} p<0.05$, compared with normal group; ${ }^{\mathrm{B}} p<0.01,{ }^{\mathrm{b}} p<0.05$, compared with model group; ${ }^{D} p<0.01,{ }^{d} p<0.05$, compared with control group

treatment of $L$. plumule flavonoids or metformin hydrochloride $(p<0.05)$ (Fig. 4). Additionally, LPF-M and LPF-H groups represented inapparent differences when compared with the control group, verifying that the supplementation of $L$. plumule flavonoids can regulate the lipid metabolism in diabetic mice.

The metabolism of lipid, glycogen, and protein are closely related to insulin regulation. Meanwhile, insulin can control the blood glucose homeostasis (Zhu et al. 2020). As shown in Fig. 5, the serum insulin levels were remarkably decrease $(p<0.05)$ in STZ-induced diabetic mice compared with the normal one, which implied the islet $\beta$ cells of diabetic mice were damaged by STZ (Li et al. 2014). However, considerable $(p<0.05)$ increases were observed in serum insulin levels of LPF and metformin hydrochloride treatments in comparison with the model group. Thus, flavonoids from $L$. plumule were able to lower serum insulin levels, improving islet $\beta$ cells function and insulin resistance.

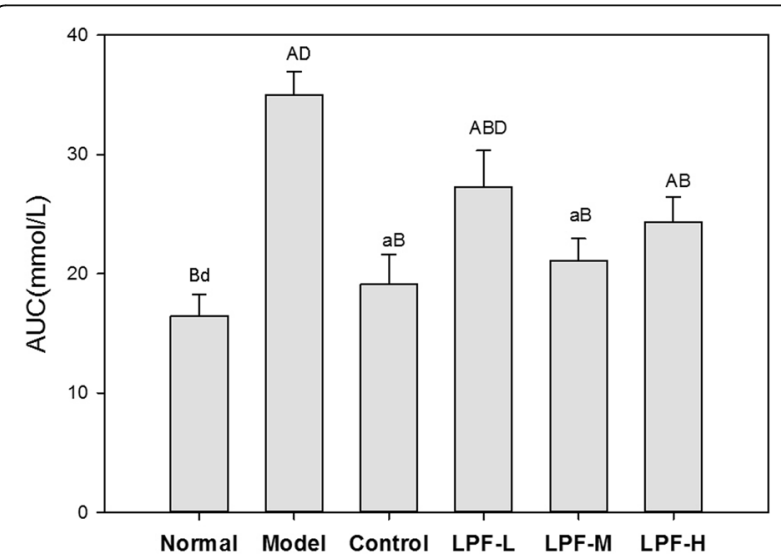

Fig. 3 Effects of flavonoids from Lotus plumule on AUC level of T2DM mice. The results were expressed as mean $\pm \mathrm{SD}$ ( $n=8 /$ group). ${ }^{A} p<0.01,{ }^{a} p<0.05$, compared with normal group; ${ }^{B} p<0.01$, ${ }^{b} p<$ 0.05 , compared with model group; ${ }^{\mathrm{D}} p<0.01,{ }^{\mathrm{d}} p<0.05$, compared with control group

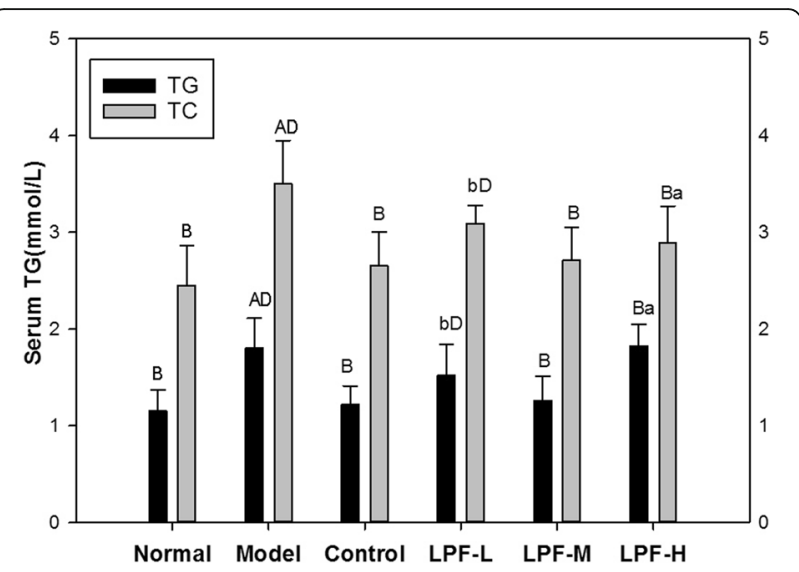

Fig. 4 Effects of LPF on serum TG and TC. The results were expressed as mean $\pm \mathrm{SD}\left(\mathrm{n}=8 /\right.$ group). ${ }^{\mathrm{A}} p<0.01,{ }^{\mathrm{a}} p<0.05$, compared with normal group; ${ }^{\mathrm{B}} p<0.01,{ }^{\mathrm{b}} p<0.05$, compared with model group; ${ }^{D} p<0.01,{ }^{d} p<0.05$, compared with control group

\section{Conclusions}

In this study, the optimum UMSE parameters and hypoglycemic activity of L. plumule extract rich in flavonoids were investigated. The extraction variables were optimized by RSM on the basis of the single factor test. The highest extraction efficiency of LPF was $2.62 \%$ at the optimal conditions as follows: microwave power 355 $\mathrm{W}$, ultrasonic power $423 \mathrm{~W}$, extraction time $15 \mathrm{~min}$, solid-liquid ratio 1:40, ultrasound/interval time $1 / 0$, and ethanol concentration $70 \%$, which was confirmed to well agreed with the predicted computed value. Moreover, $L$. plumule ethanol extract exhibited hypoglycemic effect in STZ-induced diabetic mice, showing reductions in parameters like body weight, FBG, OGTT, serum TC, TG, and insulin levels. And these antidiabetic activities might be related to the improvement of the islet $\beta$ cell

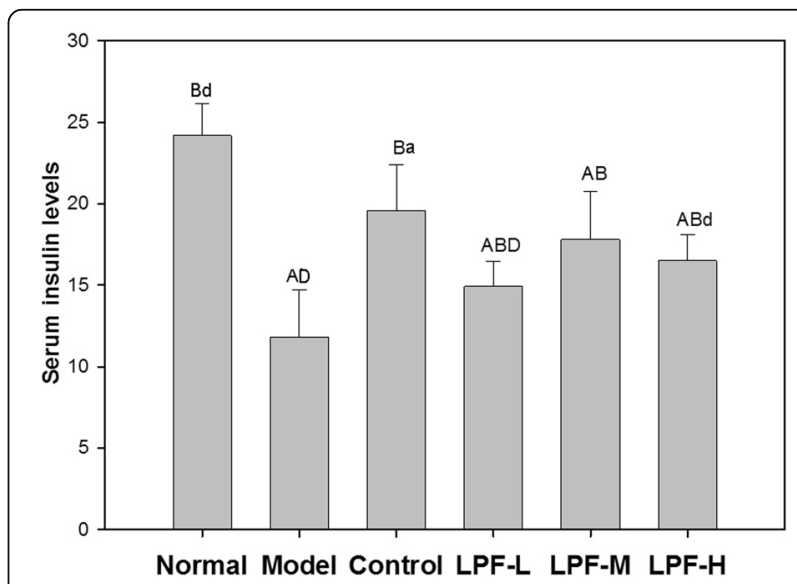

Fig. 5 Effects of LPF on insulin levels. The results were expressed as mean $\pm S D\left(n=8 /\right.$ group). ${ }^{A} p<0.01,{ }^{a} p<0.05$, compared with normal group; ${ }^{\mathrm{B}} p<0.01,{ }^{\mathrm{b}} p<0.05$, compared with model group; ${ }^{\mathrm{D}}$ $p<0.01,{ }^{d} p<0.05$, compared with control group 
function. Further experimental and clinical investigations are necessary to elucidate the regulation mechanisms of action underlying the hypoglycemic effect from L. plumule ethanol extract and look for their potential clinical applications.

\section{Abbreviations}

LPF: Lotus plumule flavonoids; FBG: fasting blood glucose; OGT: oral glucose tolerance test; TC: serum total cholesterol; TG: serum total triglycerides; T2DM: type 2 diabetes mellitus; UMSE: ultrasonic-microwave synergistic extraction; RSM: response surface methodology; BBD: Box-Behnken design; HFHS: high-fat high-sucrose diet

\section{Acknowledgements}

Not applicable.

\section{Authors' contributions}

Qiuzhe Li and Xiaoqing Li performed the experiment and wrote the article. Baodong Zheng and Chao Zhao designed the study. All authors read and approved the final manuscript.

\section{Funding}

The project was funded by Double First-Class Construction Plan of Fujian Agriculture and Forestry University (KSYLX013) and Open Project Program (BME-202004) of Key Laboratory of Brewing Molecular Engineering of China Light Industry, Beijing 100048, China.

\section{Availability of data and materials}

All data needed to evaluate the conclusions are present in the paper. Additional data related to this paper may be available upon request.

\section{Declarations}

\section{Ethical approval and consent to participate}

The animal procedures were approved by the Ethics Review Committee of College of Food Science, Fujian Agriculture and Forestry University, China (No. FS-2017-002).

\section{Consent for publication}

All authors consent to the publication.

\section{Competing interests}

The authors declare that they have no competing interest.

\section{Author details}

${ }^{1}$ College of Food Science, Fujian Agriculture and Forestry University, No.15 Shangxiadian Rd., Fuzhou, China. ${ }^{2}$ Engineering Research Centre of Fujian-Taiwan Special Marine Food Processing and Nutrition, Ministry of Education, Fuzhou, China.

Received: 16 November 2020 Accepted: 26 May 2021 Published online: 29 July 2021

\section{References}

Alara, O. R., Abdul Mudalip, S. K., \& Olalere, O. A. (2017). Optimization of mangiferin extrated from Phaleria macrocarpa fruits using response surface methodology. Journal of Applied Research on Medicinal and Aromatic Plants, 5, 82-87. https://doi.org/10.1016/j.jarmap.2017.02.002.

Alara, O. R., Abdurahman, N. H., \& Olalere, O. A. (2018). Optimization of microwave-assisted extraction of flavonoids and antioxidants from Vernonia amygdalina leaf using response surface methodology. Food and Bioproducts Processing, 107, 36-48. https://doi.org/10.1016/j.fbp.2017.10.007.

Arasi, M. A. A. G., Rao, M. G., \& Bagyalakshmi, J. (2016). Optimization of microwave-assisted extraction of polysaccharide from Psidium guajava $\mathrm{L}$. fruits. International Journal of Biological Macromolecules, 91, 227-232. https:// doi.org/10.1016/j.ijbiomac.2016.05.039.

Chan, J. C. N., Chow, E. Y. K., \& Luk, A. O. Y. (2017). Diabetes in China and the Western Pacific Region. Diabetes Mellitus in Developing Countries and Underserved Communities, 63-83
Chemat, F., Zill-e-Huma, \& Khan, M. K. (2011). Applications of ultrasound in food technology: Processing, preservation and extraction. Ultrasonics Sonochemistry, 18(4), 813-835. https://doi.org/10.1016/j.ultsonch.2010.11.023.

Chen, S., Wu, B. H., Fang, J. B., Liu, Y. L., Zhang, H. H., Fang, L. C., ... Li, S. H. (2012). Analysis of flavonoids from lotus (Nelumbo nucifera) leaves using high performance liquid chromatography/photodiode array detector tandem electrospray ionization mass spectrometry and an extraction method optimized by orthogonal design. Journal of Chromatography A, 1227, 145153. https://doi.org/10.1016/j.chroma.2011.12.098.

Chen, Z. Q., Wang, C., Pan, Y. X., Gao, X. D., \& Chen, H. X. (2018). Hypoglycemic and hypolipidemic effects of anthocyanins extract from black soybean seed coat in high fat diet and streptozotocin-induced diabetic mice. Food \& Function, 9(1), 426-439. https://doi.org/10.1039/C7FO00983F.

Chen, G. L., Fan, M. X., Wu, J. L., Li, N., \& Guo, M. Q. (2019). Antioxidant and antiinflammatory properties of flavonoids from lotus plumule. Food Chemistry, 277, 706-712. https://doi.org/10.1016/j.foodchem.2018.11.040.

Cheng, X. L., Wan, J. Y., Li, P., \& Qi, L. W. (2011). Ultrasonic/microwave assisted extraction and diagnostic ion filtering strategy by liquid chromatographyquadrupole time-of-flight mass spectrometry for rapid characterization of flavonoids in Spatholobus suberectus. Journal of Chromatography A, 1218(34), 5774-5786. https://doi.org/10.1016/j.chroma.2011.06.091.

Dahmoune, F., Spigno, G., Moussi, K., Remini, H., Cherbal, A., \& Madani, K. (2014) Pistacia lentiscus leaves as a source of phenolic compounds: Microwaveassisted extraction optimized and compared with ultrasound-assisted and conventional solvent extraction. Industrial Crops and Products, 61, 31-40. https://doi.org/10.1016/j.indcrop.2014.06.035.

Dall, T. M., Yang, W., Halder, P., Pang, B., Massoudi, M., Wintfeld, N., et al. (2014). The economic burden of elevated blood glucose levels in 2012: Diagnosed and undiagnosed diabetes, gestational diabetes mellitus, and prediabetes. Diabetes Care, 37(12), 3172-3179. https://doi.org/10.2337/dc14-1036.

Feng, C. Y., Li, S. S., Yin, D. D., Zhang, H. J., Tian, D. K., Wu, Q., et al. (2016). Rapid determination of flavonoids in plumules of sacred lotus cultivars and assessment of their antioxidant activities. Industrial Crops and Products, 87, 96-104. https://doi.org/10.1016/j.indcrop.2016.04.030.

Huang, X. Q., Tu, Z. C., Xiao, H., Li, Z., Zhang, Q. T., Wang, H., ... Zhang, L. (2013). Dynamic high pressure microfluidization-assisted extraction and antioxidant activities of sweet potato (Ipomoea batatas L.) leaves flavonoid. Food and Bioproducts Processing, 91(1), 1-6. https://doi.org/10.1016/j.fbp.2012.07.006.

Jalili, F., Jafari, S. M., Emam-Djomeh, Z., Malekjani, N., \& Farzaneh, V. (2017). Optimization of ultrasound-assisted extraction of oil from canola seeds with the use of response surface methodology. Food Analytical Methods, 11, 598612.

Jiang, Y. P., Liu, R., Liu, M., Yi, L. Z., \& Liu, S. (2018a). An integrated strategy to rapidly characterize non-targeted benzylisoquinoline alkaloids from Plumula nelumbinis ethanol extract using UHPLC/Q-orbitrap HRMS. International Journal of Mass Spectrometry, 432, 26-35. https://doi.org/10.1016/j.ijms.2018. 06.002.

Jiang, Y. P., Zi, W., Pei, Z. F., \& Liu, S. (2018b). Characterization of polysaccharides and their antioxidant properties from Plumula nelumbinis. Saudi Pharmaceutical Journal, 26(5), 656-664. https://doi.org/10.1016/j.jsps.2018.02. 026.

Jun, M. Y., Karki, R., Paudel, K. R., Sharma, B. R., Adhikari, D., \& Kim, D. W. (2016). Alkaloid rich fraction from Nelumbo nucifera targets VSMC proliferation and migration to suppress restenosis in balloon-injured rat carotid artery. Atherosclerosis, 248, 179-189. https://doi.org/10.1016/j.atherosclerosis.2016.03. 020 .

Li, J. R., Li, M., Xia, B., Ding, L. S., Xu, H. X., \& Zhou, Y. (2013). Efficient optimization of ultra-high- performance supercritical fluid chromatographic separation of Rosa sericea by response surface methodology. Journal of Separation Science, 36(13), 2114-2120. https://doi.org/10.1002/jssc.201300289.

Li, D., Peng, C., Xie, X. F., Mao, Y., Li, M., Cao, Z. X., et al. (2014). Antidiabetic effect of flavonoids from Malus toringoides (Rehd.) Hughes leaves in diabetic mice and rats. Journal of Ethnopharmacology, 153(3), 561-567. https://doi.org/10.1 016/j.jep.2014.02.026.

Liao, W. C., Lai, Y. C., Yuan, M. C., Hsu, Y. L., \& Chan, C. F. (2011). Antioxidative activity of water extract of sweet potato leaves in Taiwan. Food Chemistry, 127(3), 1224-1228. https://doi.org/10.1016/j.foodchem.2011.01.131.

Limwachiranon, J., Huang, H., Shi, Z., Li, L., \& Luo, Z. (2018). Lotus flavonoids and phenolic acids: Health promotion and safe consumption dosages. Comprehensive Reviews in Food Science and Food Safety, 17(2), 458-471. https://doi.org/10.1111/1541-4337.12333. 
Ling, Y. Y., Fun, P. S., Yeop, A., Yusoff, M. M., \& Gimbun, J. (2019). Assessment of maceration, ultrasonic and microwave assisted extraction for total phenolic content, total flavonoid content and kaempferol yield from Cassia alata via microstructures analysis. Materials Today: Proceedings, 19, 1273-1279.

Liu, T., Zhu, M., Zhang, C., \& Guo, M. (2017). Quantitative analysis and comparison of flavonoids in lotus plumules of four representative lotus cultivars. Journal of Spectroscopy, 2017, 1-9. https://doi.org/10.1155/2017/7124354.

Liu, J., Mu, T. H., Sun, H. N., \& Fauconnier, M. L. (2019). Optimization of ultrasonicmicrowave synergistic extraction of flavonoids from sweet potato leaves by response surface methodology. Journal of Food Processing and Preservation, 43(5), 1-10.

Mukherjee, P. K., Mukherjee, D., Maji, A. K., Rai, S., \& Heinrich, M. (2009). The sacred lotus (Nelumbo nucifera) - phytochemical and therapeutic profile. Journal of Pharmacy and Pharmacology, 61(4), 407-422. https://doi.org/10.1211/jpp/61. 04.0001 .

Mustapa, A. N., Martin, A., Gallego, J. R., Mato, R. B., \& Cocero, M. J. (2015). Microwave-assisted extraction of polyphenols from Clinacanthus nutans Lindau medicinal plant: Energy perspective and kinetics modeling. Chemical Engineering and Processing-Process Intensification, 97, 66-74. https://doi.org/1 0.1016/j.cep.2015.08.013

Natalia, G., \& Montori, V. M. Review: Newer second-line drugs for diabetes are not more cost-effective than sulfonylureas. Annals of Internal Medicine, 168(2), JC8.

Ono, Y., Hattori, E., Fukaya, Y., Imai, S., \& Ohizumi, Y. (2006). Anti-obesity effect of Nelumbo nucifera leaves extract in mice and rats. Journal of Ethnopharmacology, 106(2), 238-244. https://doi.org/10.1016/j.jep.2005.12.036

Rubio, M. A., Arrieta, J. L., Ruiz, M., Garrido, J., Rubio, J. A., del Llano, J., ... Raigada, F. (2008). Design and validation of a scale to assess preferences of type 2 diabetic patients towards different nutritional supplements. Nutricion Hospitalaria, 23(3), 253-262.

Sharma, B. R., Gautam, L. N., Adhikari, D., \& Karki, R. (2017). A comprehensive review on chemical profiling of Nelumbo nucifera: Potential for drug development. Phytotherapy Research, 31(1), 3-26. https://doi.org/10.1002/ptr. 5732 .

Singab, A. N. B., El-Beshbishy, H. A., Yonekawa, M., Nomura, T., \& Fukai, T. (2005). Hypoglycemic effect of Egyptian Morus alba root bark extract: Effect on diabetes and lipid peroxidation of streptozotocin-induced diabetic rats. Journal of Ethnopharmacology, 100(3), 333-338. https://doi.org/10.1016/j.jep.2 005.03.013.

Soares, J. M. D., Leal, A. E. B. P., Silva, J. C., Almeida, J. R. G. S., \& de Oliveira, H. P. (2017). Influence of flavonoids on mechanism of modulation of insulin secretion. Pharmacognosy Magazine, 13(52), 639-646. https://doi.org/10.4103/ pm.pm_87_17.

Spigno, G., \& Faveri, D. M. D. (2009). Microwave-assisted extraction of tea phenols: A phenomenological study. Journal of Food Engineering, 93(2), 210-217. https://doi.org/10.1016/j.jfoodeng.2009.01.006

Testa, R., Bonfigli, A. R., Genovese, S., De Nigris, V., \& Ceriello, A. (2016). The possible role of flavonoids in the prevention of diabetic complications. Nutrients, 8(5), 310. https://doi.org/10.3390/nu8050310.

Vasconcelos, C. F., Maranhão, H. M., Batista, T. M., Carneiro, E. M., Ferreira, F., Costa, J., ... Wanderley, A. G. (2011). Hypoglycaemic activity and molecular mechanisms of Caesalpinia ferrea Martius bark extract on streptozotocininduced diabetes in Wistar rats. Journal of Ethnopharmacology, 137(3), 15331541. https://doi.org/10.1016/j.jep.2011.08.059.

Wai, W. W., Alkarkhi, A. F. M., \& Easa, A. M. (2010). Effect of extraction conditions on yield and degree of esterification of durian rind pectin: An experimental design. Food \& Bioproducts Processing, 88(2-3), 209-214. https://doi.org/10.1 016/j.fbp.2010.01.010.

Wan, X. Z., Ai, C., Chen, Y. Q., Gao, X. X., Zhong, R. T., Liu, B., ... Zhao, C. (2020). Physicochemical characterization of a polysaccharide from Chlorella pyrenoidosa and its hypoglycemic activity and gut microbiota regulation in rats. Journal of Agricultural and Food Chemistry, 68(5), 1186-1197. https://doi. org/10.1021/acs.jafc.9b06282.

Xiong, W., Chen, X., Lv, G., Hu, D., Zhao, J., \& Li, S. (2016). Optimization of microwave-assisted extraction of bioactive alkaloids from lotus plumule using response surface methodology. Journal of Pharmaceutical Analysis, 6(6), 382388. https://doi.org/10.1016/j.jpha.2016.05.007

Xu, H. J., Shi, X. W., Ji, X., Du, Y. F., Zhu, H., \& Zhang, L. T. (2012). A rapid method for simultaneous determination of triterpenoid saponins in Pulsatilla turczaninovii using microwave-assisted extraction and high-performance liquid chromatography-tandem mass spectrometry. Food Chemistry, 135(1), 251-258. https://doi.org/10.1016/j.foodchem.2012.04.081.
Yan, X., Yang, C. F., Lin, G. P., Chen, Y. Q., Miao, S., Liu, B., \& Zhao, C. (2019). Antidiabetic potential of green seaweed Enteromorpha prolifera flavonoids regulating insulin signaling pathway and gut microbiota in type 2 diabetic mice. Journal of Food Science, 84(1), 165-173. https://doi.org/10.1111/1750-3 841.14415

Zhao, C., Yang, C. F., Wai, S. T. C., Zhang, Y. B., Portillo, M. Y., Paoli, P., ... Cao, H. (2019). Regulation of glucose metabolism by bioactive phytochemicals for the management of type 2 diabetes mellitus. Critical Reviews in Food Science and Nutrition, 59(6), 830-847. https://doi.org/10.1080/10408398.2018.1501658.

Zhu, C. P., Zhai, X. C., Li, L. Q., Wu, X. X., \& Li, B. (2015). Response surface optimization of ultrasound-assisted polysaccharides extraction from pomegranate peel. Food Chemistry, 177, 139-146. https://doi.org/10.1016/j. foodchem.2015.01.022.

Zhu, X. A., Ouyang, W., Lan, Y. Q., Xiao, H., Tang, L., Liu, G., ... Cao, Y. (2020). Antihyperglycemic and liver protective effects of flavonoids from Psidium guajava L. (guava) leaf in diabetic mice. Food Bioscience, 35, 100574.

\section{Publisher's Note}

Springer Nature remains neutral with regard to jurisdictional claims in published maps and institutional affiliations.
Ready to submit your research? Choose BMC and benefit from:

- fast, convenient online submission

- thorough peer review by experienced researchers in your field

- rapid publication on acceptance

- support for research data, including large and complex data types

- gold Open Access which fosters wider collaboration and increased citations

- maximum visibility for your research: over $100 \mathrm{M}$ website views per year

At BMC, research is always in progress.

Learn more biomedcentral.com/submissions 